\title{
El debate Kelsen-Hart. Sobre la sanción normativa. Una mirada más allá del "Último mohicano"
}

Andrés Botero Bernal

Universidad Industrial de Santander, Colombia

(c) $\underset{\mathrm{Br}}{\mathrm{i}}$ 


\title{
El debate Kelsen-Hart. Sobre la sanción normativa. Una mirada más allá del "Último mohicano"
}

\begin{abstract}
Resumen: en este escrito se menciona el debate entre Kelsen y Hart en torno a la sanción (castigo) como un elemento estructural o no de la norma jurídica. Se señala que dicho debate refleja, entre otras cosas, los distintos fundamentos filosóficos de ambos autores, la diferencia en torno a la concepción cultural del derecho en Europa continental y en Inglaterra, y la búsqueda de Hart de depurar algunas posturas kelsenianas con el fin de consolidar el positivismo y ubicarlo de mejor manera en el contexto del Common Law.
\end{abstract}

Además, con base en lo anterior, en este escrito se ratifica que el positivismo, en general, y el pensamiento hartiano, en particular, no están en vía de extinción (que Hart no fue el "último mohicano"), a pesar de lo que suele afirmarse al respecto desde algunas corrientes neoconstitucionalistas y no-positivistas contemporáneas.

Palabras clave: Hart, Kelsen, norma jurídica, castigo, sanción.

\section{The Kelsen-Hart debate on normative sanction: a look beyond "the last of the mohicans"}

\begin{abstract}
Kelsen and Hart about the sanction (punishment) as a structural element or not of the legal norm.

Further, this paper pointed out that this debate reflects, among other things, the different philosophical foundations of both authors, the difference between the cultural conception of law in continental Europe and in England, and it shows that Hart try to purify some of the Kelsenian positions in order to consolidate positivism and to locate it better in the context of the Common Law.

Based on the above, this paper affirms that positivism, in general, and Hartian thinking, in particular, are not on the verge of extinction (which Hart was not the "last Mohican"), despite what is usually affirmed in this respect from some contemporary neoconstitutionalist and nonpositivist theories.
\end{abstract}

Keywords: Hart, Kelsen, legal norm, punishment, sanction.

Fecha de recepción: 6 de junio de 2017

Fecha de aceptación: 1 de septiembre de 2017

Forma de citar (APA): Botero Bernal, A. (2017). El debate Kelsen-Hart sobre la sanción normativa: una mirada más allá del "Último mohicano". Revista Filosofía UIS, 16(2), doi: http://dx.doi.org/10.18273/ revfil.v16n2-2017014

Forma de citar (Harvard): Botero Bernal, A. (2017). El debate Kelsen-Hart sobre la sanción normativa: una mirada más allá del "Último mohicano". Revista Filosofía UIS, 16(2), 303-324.

Andrés Botero Bernal: colombiano. Profesor titular de la Escuela de Filosofía de la Universidad Industrial de Santander. Doctor en Derecho por la Universidad de Buenos Aires. Doctor en Derecho por la Universidad de Huelva.

Correo electrónico: botero39@gmail.com

*Artículo de investigación científica y tecnológica. 


\section{El debate Kelsen-Hart. Sobre la sanción normativa. Una mirada más allá del "Último mohicano"}

\section{Diferentes lecturas sobre Hart}

Hart ha pasado a la historia de la iusfilosofía de forma diferenciada según la lectura que de él se ha impuesto en la cultura jurídica de nuestra época. Una lectura es la que circula entre los ámbitos de formación de abogados (en los cuales, raramente se presta atención a la historicidad de la disciplina en general y de la iusfilosofía en especial) y la otra la que predomina en los territorios de los iusfilósofos en sentido estricto (quienes raramente están en condiciones de afectar el entorno educativo, ya porque esos entornos consideran a la iusfilosofía como un saber menor, ya porque la brecha entre eruditos y no eruditos hace casi imposible la comunicación).

La primera lectura, que a la postre es la más determinante por sus efectos culturales amplios, sabe de Hart pero en lo que se circunscribe al debate que tuvo con Dworkin, debate que es leído, la mayoría de las veces, por lo menos en Latinoamérica donde tanto empuje ha tenido el neoconstitucionalismo, como el enfrentamiento del último de los Mohicanos $^{1}$ (Hart) versus Hércules ${ }^{2}$ (Dworkin)

\footnotetext{
${ }^{1}$ Haciendo alusión a la novela "El último mohicano" (1826) de James Fenimore Cooper. Esto es, que Hart sería el último de su estirpe, el positivismo, que lucha por su no desaparición.

${ }^{2}$ Como referencia al juez-súper-poderoso planteado por Dworkin, que es capaz de dar con la única solución correcta, moralmente hablando, ante cada caso jurídico problemático. "Haríamos bien en considerar de qué manera, en los casos adecuados, un juez filósofo podría elaborar teorías sobre qué es lo que exigen la intención de la ley y los principios jurídicos. Nos encontraremos con que diseñaría tales teorías de la misma manera que un árbitro filósofo delinea el carácter de un juego. Para este propósito he inventado un abogado dotado de habilidad, erudición, paciencia y perspicacia sobrehumanas, a quien llamaré Hércules. Supongo que Hércules es juez en alguna jurisdicción importante de los Estados Unidos. Supongo que acepta las principales normas constitutivas y regulativas no controvertidas del derecho en su jurisdicción. Es decir que acepta que las leyes tienen el poder general de crear y extinguir derechos, y que los jueces tienen el deber general de ajustarse a las decisiones
} 
(esta primera lectura es descrita, entre otros, por: Lloredo, 2017). Me preocupa, seriamente, que esta lectura no solo sea la que predomine en los ámbitos de formación de nuevos abogados, sino también que termine siendo la que se imponga para el futuro corpus doctrinario de la filosofía del derecho cuando esta aluda a lo que aconteció en la disciplina en la segunda mitad del siglo XX.

La segunda lectura, propia de especialistas, sabe claramente que Hartfue mucho más que lo anterior, de manera tal que acusa, con razones, a la primera lectura pues reduce al autor inglés -en su afán de crear esquemas básicos memorizables adecuados con la enseñanza, cada vez más restringida, de las humanidades-, al considerarlo como el fallido contradictor de Dworkin y como la última columna del edificio positivista. El especialista sabe que Hart no ha representado el papel del "Último mohicano" que desea sobrevivir ante los impulsos imbatibles de la civilización no-positivista, puesto que, por lo menos en la tradición anglosajona, el positivismo jurídico (como teoría de la existencia del derecho y los sistemas jurídicos) es la postura dominante, para algunos, o por lo menos muy fuerte, para otros, representada por autores como Joseph Raz, Andrei Marmor, Wil Waluchow, John Gardner, Leslie Green y Ken Himma, entre otros, quienes han continuado con el pensamiento hartiano, sin negarse el derecho a hacerle precisiones, claro está. Incluso, los iusnaturalistas contemporáneos en dicha tradición (pienso en John Finnis y Mark Murphy, por dar dos casos) y los no-positivistas (como Kevin Toh y Stefan Sciaraffa), asumen que la teoría hartiana es más o menos correcta en lo fundamental, aunque incompleta en lo que atañe a la justificación del sistema jurídico.

Así las cosas, ¿qué hacer? Sería ingenuo creer que la primera lectura se desvanecerá espontáneamente entre más (se) escriban (entre ellos) los expertos al respecto. Hay que poner en evidencia, pero para públicos más amplios, aquellas cosas del pensamiento hartiano que pueden interesar a estudiantes y profesores de derecho contemporáneos para desvirtuar la imagen errada de que el positivismo está casi extinto, como los mohicanos, de un lado, y de que el pensamiento hartiano solo dio para un debate con Dworkin, del otro.

Al pensar qué podrían ser esas cosas, se deslizó entre las primeras posibilidades analizar aquella parte de la vida de Hart que tanto interés despierta en los estudiantes cuando se menciona la vida del autor inglés: que trabajó en el servicio de espionaje y contraespionaje (MI5) del Reino Unido durante la Segunda Guerra Mundial y que tanto él, como su esposa ${ }^{3}$, fueron investigados

anteriores de su tribunal o de tribunales superiores cuyas bases lógicas, como dicen los juristas, abarquen el caso que tienen entre manos" (Dworkin, 1989, p. 177).

${ }^{3}$ En la década de los 50 y 60 del siglo pasado, en Inglaterra, se produjo un gran escándalo que envolvió a su servicio secreto. Un importante espía inglés (Kim Philby) resultó ser un agente soviético infiltrado. Durante la investigación de este sonado caso, una testigo involucró como posible espía a Jenifer Hart, esposa de Herbert Hart. No se pudo comprobar

Revista Filosofía UIS, Vol. 16, No. 2, julio-diciembre de 2017 

mirada más allá del "Último mohicano"

por ser presuntos espías rusos durante la Guerra Fría (acusaciones que nunca se comprobaron). Pero, si se investiga a fondo, y no solo desde las biografías (Lacey, 20044; Torres, 2005, pp. 359-368), no vislumbro alguna relación fuerte y seria de aquellos acontecimientos con la iusfilosofía, por más que alguien haya dicho, sin demostrarlo, todo lo contrario ${ }^{5}$.

Al desechar esta ruta, pasé a otro aspecto que, si bien es un asunto propio de la historia de la iusfilosofía, en el fondo deja en claro, por lo menos, dos enseñanzas muy valiosas: una para la filosofía del derecho y otra para el derecho comparado contemporáneos. Todo con el fin de mostrar a un Hart más proactivo que el que se quiere imponer en muchas facultades de derecho.

Me refiero al debate que sostuvo con Kelsen sobre las normas sancionadoras, que pone de relieve (i) la distancia que hay entre estos dos autores, especialmente por sus diferentes influencias filosóficas (lo que constituye una enseñanza para la iusfilosofía); (ii) el papel que jugó Hart como consolidador del positivismo jurídico de su época (lo que implica una enseñanza para la historia de la iusfilosofía); y, (iii), la diferencias en la concepción cultural del derecho, entre el sistema jurídico continental con el Common Law (lo que sirve de enseñanza para el derecho comparado).

\section{El debate Hart - Kelsen en torno a la estructura de las normas}

Hart fue decisivo en la consolidación de las posturas normativistas de Kelsen en su fase final, esto es, la que corresponde a los trabajos de Kelsen una vez radicado en Estados Unidos. Hart logró, vía la aguda crítica y la pertinente polémica que tanto le gustaba (Raz, 1993, pp. 28-29), varias precisiones e incluso correcciones del propio Kelsen frente a su Teoría Pura del Derecho (en adelante TPD) en general y la teoría de la normatividad en especial (Spaak, 2005), las que le permitieron a esa obra no solo consolidarse mejor ante las críticas sino también adecuarse ante los nuevos escenarios que le suponía el demostrar, como lo intentó Kelsen, que su teoría, por ser general, también era aplicable al Common Law (Clark, 1969). Estas críticas de Hart a Kelsen pueden concentrarse en varios campos, pero quisiera

que fuese espía o que hubiese dado información privilegiada a los soviéticos, a pesar de que en los años previos a la Segunda Guerra Mundial fue miembro del partido comunista y contactada por el servicio secreto ruso. A pesar de no existir prueba al respecto, esta sospecha siempre la acompañó en vida, así como al propio Herbert, y varias veces fue sacada a relucir ante los medios de comunicación (Rosamund, 1991, p. 181; White, 2005, pp. 333-335; y la autobiografía de Jenifer Hart (1998).

${ }^{4}$ Esta autora deja en claro lo mucho que afectó a Hart estas terribles acusaciones.

5 "Los métodos para analizar la información por Hart (cuando trabajó en el MI5) luego fueron usados para pensar el derecho de otra forma". El texto entre paréntesis es propio. (Carranza, 2014, p. 2). 
resaltar, por el momento, tres: i) ¿cuál es la norma base del sistema jurídico? ; ii) ¿en qué consiste la unidad del sistema normativo? (Hart, 1968, pp. 208-270; en español: Hart, 1994, pp. 383-421); y, iii) ¿cuál es la estructura formal de la norma jurídica? (Bulygin y Mendonca, 2005, pp. 11-24; Robles, 1980, pp. 47-64; Spaak, 2005; García, 2011, pp. 171-212).

Estos tres aspectos, que han sido bien estudiados por los expertos, no pueden ser interpretados como una búsqueda de la destrucción de la Reine Rechtslehre en tanto Hart creía que el pensamiento general kelseniano, en términos generales, era correcto y, además, era consciente de que Kelsen era un soporte crucial para el positivismo en el contexto del Common Law (Clark, 1969, pp. 195-196), especialmente en su lucha contra el dogmatismo derivado de las tradiciones propias a las que ambos se enfrentaban. Se trataría más bien de importantes precisiones conceptuales, bajo la égida analítica, que buscaban, vía crítica, la consolidación de una postura general (el positivismo) al reconocer que la TPD tenía, según el inglés, algunas limitaciones comprensivas del fenómeno normativo propio del sistema anglosajón, pero que ellas no comprometían la validez general de la matriz común que los unía (matriz común que los conduce a un autor que tanto influyó en ellos dos: John Austin).

Quisiera explicar mejor lo antes señalado en relación con el tercero de los puntos anteriores: la estructura de las normas jurídicas en sentido estricto. Kelsen consideró, inicialmente, que toda norma jurídica, para ser tal, implica una sanción o castigo a la transgresión ${ }^{7}$; esto es, una prohibición fundada en una amenaza estatal a quien transgreda el imperativo base del legislador, este último en sentido amplio (Kelsen, 2005, pp. 48-50 y pp. 123-129; Kelsen, 1941, pp. 75-97). Dicho con un ejemplo de manual, una norma jurídica sería la sanción (pena de prisión) a quien transgreda un imperativo (no matar), de manera tal que la norma podría explicarse lógicamente a partir de dos mandatos regidos por el principio de imputación y no de causalidad: el primero sería aquel de lo que se desea se haga o no se haga (no debes matar), y el segundo sería en sentido estricto la verdadera norma jurídica, que consagra el deber de sancionar a quien transgreda el primer imperativo o imperativo base (el que matare a otro deberá ser castigado con una pena de prisión de tantos a tantos años de prisión).

\footnotetext{
"Para Kelsen sería la "norma hipotética fundamental" mientras que para Hart sería la "regla de reconocimiento". La negativa de Kelsen frente a esta teoría hartiana se encuentra en: (Kelsen, 2005, p. 229, nota 134, parágrafo 34, i). Sobre la teoría de la regla de reconocimiento, ver: (Hart, 1998, pp. 125-137; Bulygin, 1976, pp. 31-39; Gómez, 1976, pp. 47-53; Spaak, 2005, pp 404-412; y Márquez, 1985, pp. 163-188; entre otros).

La transgresión es la violación de la obligación normativa, esto es, la violación de la prohibición. La sanción solo puede imputarse cuando previamente se ha imputado una transgresión. Entonces, la coacción es, eminentemente, un sistema de castigo ante el imputado como transgresor. Así lo señaló Kelsen en "El derecho como orden constrictivo", transcrito en: (Kelsen y Cossio, 1952, p. 73).
} 

mirada más allá del "Último mohicano"

Incluso esta posición, de que el derecho está integrado por normas prohibitivas, llevó al autor austriaco a plantear la tesis de la completud del derecho, en la medida que aquello que no está prohibido se entiende permitido, de manera tal que nada escapa a la regulación del derecho: o está prohibido o está permitido. En consecuencia, no habría lagunas pues el derecho siempre es un orden completo, lo cual generó una serie de críticas las cuales no podremos enunciar pues nos desvían de nuestro interés (cfr. Bulygin, 2009, pp. 11-14). Sin embargo, el principio de completud fue abandonado por su propio autor casi al finalizar su vida académica (Kelsen, 1962).

Volviendo sobre la teoría de las normas, especialmente su aspecto de que toda norma es una prohibición respaldada por una sanción, Hart llamó la atención de Kelsen al preguntarse: ¿qué hacer entonces con aquellas normas propias de sistemas jurídicos basados más en el principio de colaboración que en el de prohibición, que no sancionan la transgresión, sino que recompensan, permiten, autorizan o informan, desde el derecho, sobre cómo obtener un resultado? Es que aceptar normas no prohibitivas supondría cuestionar no solo la estructura coercitiva de la norma sino también la teoría de la completud del sistema jurídico.

De esta manera, para Hart, si se mira desde la práctica social de un partícipe del sistema (Hart, 1998, p. 111), no todas las normas obedecen a la estructura kelseniana; a lo sumo, solo las normas que Hart denominó como "reglas primarias", que son aquellas reglas sociales que se aplican en ciertos contextos primarios, que tienen por objeto - directo o indirecto- regular la conducta humana imponiendo obligaciones; incluso, cuando una norma primaria ordena obedecer otra, sigue siendo la conducta humana la principal destinataria. Entonces, entre las normas que no corresponden con la estructura coercitiva kelseniana están las reglas cuya consecuencia jurídica sería una recompensa, de un lado, y las reglas secundarias (de cambio, de adjudicación y de reconocimiento) cuya consecuencia jurídica sería una potestad frente a reglas primarias, del otro. Frente a este tipo de reglas, Hart escribió:

Pero existen importantes clases de normas jurídicas respecto de las cuales esta analogía con órdenes respaldadas por amenazas no cabe en absoluto, por cuanto ellas cumplen una función social totalmente distinta. Las reglas jurídicas que definen la manera de realizar contratos, celebrar matrimonios u otorgar testamentos válidos, no exigen que las personas actúen de modos determinados, lo quieran o no. Tales normas no imponen deberes u obligaciones. En lugar de ello, acuerdan a los particulares facilidades para llevar a cabo sus deseos, al otorgarles potestades para crear, mediante ciertos procedimientos específicos y bajo ciertas condiciones, estructuras de facultades y deberes dentro del cuadro coercitivo del derecho. La potestad así conferida a los individuos para dar forma a sus relaciones jurídicas con los demás mediante contratos, testamentos, matrimonios, etc., es uno de los grandes aportes del derecho a la vida social; y es una característica que queda oscurecida si se representa a todo el derecho como una cuestión de órdenes respaldadas por amenazas (Hart, 1998, p. 35). 
Además, este esquema de sanción-positiva se ve más claramente con las reglas secundarias, entendidas estas como prácticas sociales aceptadas (desde el punto de vista interno, esto es, desde el participante del sistema (Hart, 1998, p. 111) mediante las cuales se establece la creación, la adjudicación y el reconocimiento sobre qué es $-y$, por tanto, sobre qué no es- norma jurídica. Las reglas de cambio serían mandatos que, en la práctica social, determinan la forma de crear, modificar o extinguir reglas primarias; es decir, la facultad a "un individuo o cuerpo de personas a introducir nuevas reglas primarias para la conducción de la vida del grupo, o de alguna clase de hombres que forman parte de él, y a dejar sin efecto las reglas anteriores" (Hart, 1998, p. 119). Las de adjudicación son aquellas que "facultan a determinar, en forma revestida de autoridad, si en una ocasión particular se ha transgredido una regla primaria" (Hart, 1998, p. 120) ${ }^{8}$. Y, finalmente, la tercera, sería la norma base del sistema jurídico en tanto ella le permite al grupo social reconocer una regla primaria (Hart, 1998, pp. 117-120, entre otras), de manera tal que es la "regla última de un sistema" o "criterio supremo de validez" (Hart, 1998, p. 133) verificable en tanto es una "cuestión de hecho" (Hart, 1998, p. 137); regla esta que, al parecer, impone un deber a los adjudicadores de aplicar las reglas primarias reconocidas ${ }^{9}$.

La característica común de estas reglas secundarias, como ya dije, es que no corresponden con el esquema kelseniano, en general al de norma como un deberser proposicional sin contacto con la realidad, y en especial al de norma-negativa o norma-sanción, propio de entender el derecho solo como coerción (fruto, ambas cosas, de la herencia kantiana del autor austriaco); y no corresponden pues la sanción de dichas reglas, en un sentido amplio, consiste en la potestad de crear, modificar, extinguir, validar o resolver conflictos entre reglas primarias. En consecuencia, para Hart (por su herencia humeana), no todas las reglas pueden ser reducidas a ser meras prohibiciones con mandatos coercitivos en sentido estricto, pues eso supondría, de un lado, la imposibilidad de explicar en la práctica social (i) ciertas reglas (como las de recompensa y las secundarias) y, del otro, (ii) la presencia de esencias morales en el derecho ${ }^{10}$.

\footnotetext{
${ }^{8}$ En las reglas de adjudicación se incluye tanto las que señalan qué individuos tienen esta facultad (jueces) y el procedimiento para hacer tal determinación.

${ }^{9}$ Señalo "al parecer", porque este es un aspecto debatido. La posición tradicional señala que la regla de reconocimiento impone un deber del juez de aplicar las reglas primarias (v.gr., Raz, 1980, cap. VIII, 3; Ruiz, 1990; etc.). En contra está Bulygin: "Sin duda, normalmente los jueces tienen el deber de (es decir, están obligados a) decidir los casos conforme a las normas válidas. Para poder cumplir esta obligación los jueces tienen que usar la regla de reconocimiento, pero esta obligación no surge de la regla de reconocimiento misma, sino de una determinada norma del sistema, identificada conforme a la regla de reconocimiento" (Bulygin, 1976, p. 39). Ver el debate surgido al respecto: (Bulygin, 1991; Ruiz, 1991).

${ }^{10}$ La convivencia exige un mínimo de normas morales en el derecho, pero eso no supone confundir la moral con el derecho, de una parte, ni declararse iusnaturalista, del otro: "Tanto el derecho como la moral incluyen reglas que rigen la conducta de los individuos en situaciones que se repiten constantemente a lo largo de la vida, y no en ocasiones o
} 

mirada más allá del "Último mohicano"

Ahora bien, Kelsen, al darse cuenta de la fuerza intrínseca de la crítica hartiana (que supone, entre otras cosas, un reto de la aplicabilidad de la TPD en el contexto del Common Law) y para poder mantener la uniformidad de su modelo, consideró -en su segunda edición de la TPD- a las normas con sanción-positiva como "normas incompletas" o "normas no independientes" (Kelsen, 2005, pp. 63-70, parágrafo 6, d y e; Cracogna, 1986, pp. 50-52), las cuales, sin embargo, solo se vuelven completas o independientes una vez pueden articularse con una sanción-negativa, con una coacción ${ }^{11}$ :

De lo dicho resulta que un orden jurídico, aunque de ninguna manera todas sus normas estatuyan actos coactivos, puede con todo ser caracterizado como un orden coactivo, en cuanto todas las normas que de por sí no estatuyen actos coactivos, y que, por tanto, no imponen obligaciones, sino que sólo facultan o permiten positivamente la producción de normas, son normas no independientes que sólo valen en conexión con una norma que estatuye un acto coactivo. Pero tampoco todas las normas que estatuyen actos coactivos obligan, sino sólo aquellas que estatuyen el acto coactivo como reacción -es decir, como sanción- contra determinada conducta humana, obligando, pues, a la conducta contraria (Kelsen, 2005, p. 70).

Para entender la importancia de este cambio de la postura kelseniana, insuficiente para algunos y suficiente para otros, hay que explicar, aunque sea someramente, que, para Kelsen, el concepto de norma va más allá de los enunciados normativos que emite el legislador. La norma jurídica, en sentido estricto, es la que se construye a partir de varios enunciados del legislador general, de manera tal que si tengo ante mí un enunciado (un artículo de una ley o de un decreto, por ejemplo) con un sentido positivo (que recompensa, permite, autoriza o informa), no estamos ante una norma completa o en sentido estricto. Le correspondería al juez, por medio de la interpretación (Kelsen, 2005, pp. 349-356), articular dicho enunciado con otro(s) que establezca(n) una sanción-negativa, lo que demostraría,

actividades especiales, y aunque ambos pueden incluir mucho de lo que es peculiar a las necesidades reales o imaginadas de una particular sociedad, tanto el derecho como la moral formulan exigencias que, obviamente, tienen que ser satisfechas por cualquier grupo de seres humanos para poder convivir. Por ello es que en ambos hallaremos algún tipo de prohibición de la violencia a las personas o a la propiedad, y algunas exigencias de honestidad y veracidad" (Hart, 1998, p. 214). "La reflexión sobre algunas generalizaciones muy obvias referentes a la naturaleza humana y al mundo en que los hombres viven, muestra que en la medida en que ellas sigan siendo verdaderas, hay ciertas reglas de conducta que toda organización social tiene que contener para ser viable. Tales reglas constituyen de hecho un elemento común al derecho y a la moral convencional de todas las sociedades que han alcanzado el punto en que uno y otra se distinguen como formas diferentes de control social" (Hart, 1998, p. 238).

${ }^{11}$ Una explicación más amplia sobre la coacción (sanción negativa) y el rechazo kelseniano a las sanciones positivas, en: (Bobbio, 1976, pp. 14-30). Bobbio se propuso demostrar que la consideración kelseniana de la coacción como elemento estructurante de la norma, frente al rol secundario que le asigna a la recompensa como sanción, fue una concesión que el austríaco terminó haciendo, sin darse cuenta, al funcionalismo. 
una vez más, la discrecionalidad judicial (Kelsen, 2005, p. 354). El juez debe cambiar el sentido positivo del enunciado para leerlo desde el sentido negativo o castigador, propio de las normas jurídicas en sentido estricto o normas independientes. Entonces, si el legislador emite un enunciado que dice que "cualquier ciudadano tiene derecho, si reúne los requisitos A y B, a transitar libremente en su vehículo" o que "el procedimiento de creación de un decreto municipal son X y Y", el juez asume que detrás de todo ello hay una norma sancionatoria que podría transcribirse de la siguiente manera: "el ciudadano que transite con su vehículo, sin cumplir los

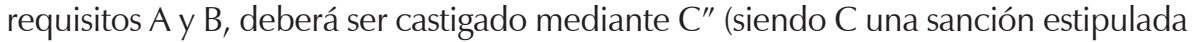
en algún otro enunciado normativo y que el juez considere aplicable, en el marco del propio sistema vigente, al caso que juzga) o "si no se respeta el procedimiento $X$ y $\mathrm{Y}$ el decreto municipal debe ser declarado nulo" (siempre y cuando la nulidad pueda ser inferida de otros enunciados normativos del sistema, como suele suceder para este tipo de ejemplos). Así, toda regla secundaria o todo enunciado permisivo sería la premisa inicial de una norma sancionadora.

Pero, ¿qué diría un hartiano sobre esto? En primer lugar, que la distinción entre regla primaria y regla secundaria no es tan radical como lo han pretendido ver los críticos, en tanto dichas categorías no están incomunicadas entre sí, de un lado, y que no son categorías ontológicas por fuera del observador, sino que solo son visibles según la perspectiva que asuma el operador jurídico, del otro. De esta manera, desde cierta óptica es posible ver una regla primaria de lo que, desde otro lente (esto es, desde otra práctica social propia del punto de vista interno), sería una regla secundaria. De manera tal, que Kelsen cuando ve una regla primaria con sanción negativa detrás de toda regla permisiva o regla secundaria o regla de cambio, no contradice a Hart. En segundo lugar, tratándose de las reglas secundarias de cambio, para seguir el ejemplo anterior del decreto municipal, la nulidad no es una sanción negativa, pues no puede "ser asimilada a un castigo establecido por una regla como estímulo para que uno se abstenga de las actividades que la regla prohíbe" (Hart, 1998, p. 42); verbigracia, la decisión del árbitro de que un disparo del balón hacia la portería no fue un gol, no es un castigo al jugador, sino que es parte misma de las reglas que establecen cómo se hace una anotación (Hart, 1998, p. 44) ${ }^{12}$. En tercer lugar, que Kelsen sigue sin demostrar por qué es preferible encontrar una sanción negativa detrás de una regla secundaria o de una regla permisiva cuando también es posible encontrar, para el mismo caso, una consecuencia positiva (por ejemplo, que si se sigue el procedimiento el decreto municipal debe ser imputado como válido).

\footnotetext{
${ }^{12}$ Esto es, si seguimos la terminología kelseniana, que si la norma jurídica es una amenaza de castigo a quien se le imputa haber desobedecido un imperativo base, ila nulidad a quien está amenazando?, ¿qué imperativo base se protege con la nulidad? Obviamente, los debates no terminaron aquí, pues los críticos de Hart han considerado que si bien la nulidad no se comporta, claramente, como un castigo penal, sí puede ser vista como un castigo que amenaza a quien hace el contrato o la norma, incentivándolo a que respete el procedimiento.
}

Revista Filosofía UIS, Vol. 16, No. 2, julio-diciembre de 2017 


\section{Los efectos del debate en torno a la estructura de la norma jurídica}

La respuesta kelseniana, provocada ante los reclamos de Hart, ha tenido, por lo menos, una consecuencia sistémica y otra cultural. Frente a la consecuencia sistemática (esto es, sobre cómo articular una experiencia concreta con una teoría general), es que Kelsen, en vez de reconocer que no todas las normas obedecen a la misma estructura y a la misma función social (represión para conseguir la paz), termina por uniformarlas considerando el derecho como "una reacción contra lo ilícito" (Kelsen, 2005, p. 126). Es decir, por su afán de dar con lo general de todo sistema jurídico, cuando Hart le planteó que no toda norma se construye como prohibición garantizada con una coerción, Kelsen terminó precisando, para los kelsenianos, o maquillando, para los hartianos, su teoría inicial.

Y digo maquillando su teoría porque, en cierto sentido, parecería que el vuelco kelseniano fue insuficiente (como lo señaló el propio Hart (1998, pp. 4548), al considerar este cambio como una mera argucia teórica ${ }^{13}$ ), pues Kelsen siguió sosteniendo, a pesar de todo, que las normas solo son tal, en el sentido más estricto de la palabra, si castigan.

En lo que respecta al asunto cultural, lo que se le reclama a los contrincantes, en especial a Kelsen, está en un presunto error epistemológico: ¿es válido creer que hay algo en común en la concepción de norma en todos los sistemas jurídicos? Pretender que todos los sistemas jurídicos tienen unos mismos componentes formales, de manera tal que sobre eso que los une es posible hacer una teoría general (como lo creía Kelsen y Hart (1998, pp. 3-4), aunque en diferente medida), aplicable a cualquier sistema, conlleva una tensión difícil de resolver para la ciencia jurídica en general y para el positivismo en especial (Culver, 2001): ¿lo jurídico, que incluye tanto la ciencia como la normativa, debe construirse de cara a su contexto cultural y político o atendiendo a las formas de la teoría general? Cualquier respuesta es problemática. Por ejemplo, si se afirma que el derecho es más cultural que formal, entonces los estudios generales caerían en desgracia, pero ¿cómo podría identificarse lo jurídico en una cultura si no hay claridad previa en las formas generales que son justo las que permiten tal identificación? Dicho con otras palabras, ¿es posible hacer un análisis cultural sin haber realizado previamente un juicio formal y general de lo que es derecho? Sin embargo, ¿es posible plantear una teoría formal de identificación general de lo jurídico por fuera del contexto cultural de quien formula la teoría? Si es imposible -o por lo menos muy difícil- salir del esquema cultural propio, ¿cómo una teoría formal puede ser general?

\footnotetext{
${ }^{13}$ Claro está que este juicio hartiano no se circunscribió solo a la teoría de la sanción-positiva (norma no-independiente) y de la sanción-coerción (norma independiente). (Hart, 1983, pp. 286-308, Essay 14). También publicado en: UCLA law review, núm. 10, 1962-3, pp. 709728. Ver especialmente: "Rules of Law in a descriptive sense" $y$ "The definition of delict".
} 
Todo esto nos lleva, necesariamente, al reto de comprender lo jurídico reconociendo la importancia tanto de los aportes de las teorías generales como de los estudios culturales contextualizados, que -si se interpretan conjuntamentearrojarían muchos beneficios para la observación del derecho, pero si se mira uno en desmedro del otro, darían visiones muy limitadas.

Entonces, en el caso que nos ocupa, la norma jurídica, consideramos que la teoría general permite clarificar y, por tanto, identificar qué es y qué no es norma, para luego contextualizar el sentido de la norma en su cultura más inmediata. Solo resolviendo la pregunta formal previa, podemos hacer un análisis contextualizado; pero la respuesta formal dada no se aleja, por lo menos no en el caso que nos ocupa, del contexto cultural de cada autor. Y no se aleja, por consideraciones cognitivas (desde la teoría de la intencionalidad del conocimiento, ninguna idea planteada surge por fuera de las experiencias previas de quien la enuncia) y por las familias jurídicas que rodean a los autores que analizamos. Veamos.

Un aspecto que diferencia parcialmente el Common Law (entendido aquí desde su faceta cultural-histórica y no desde las propuestas de autores imperativistas como Austin) del sistema jurídico continental, está fundado en su orientación política al momento de construir el Estado y, por tanto, el derecho normativo. Mientras el Estado inglés se construyó bajo el empirismo, el pragmatismo, el realismo y el historicismo (ratificado por un modelo consuetudinario-judicial, esto es, de costumbres que son interpretadas por los jueces en defensa del precedente ${ }^{14}$ ); el Estado, en el Continente europeo, se construyó de otra forma, más racionalista, formalista, estatalista y legicentrista si se quiere (Whittaker, 2008, pp. 46-53; Falcón y Tella, 2005, pp. 83-86). Y este fundamento diferenciador favoreció y se vio favorecido en una actitud política de qué se espera del Estado. En el Common Law el poder público no ha sido visto tanto - es decir, no de la misma manera como ha sucedido en el Continente-como un mero motor creador de derecho y sancionador (castigador) de las desviaciones de los ciudadanos ante ese mismo derecho, sino también como un poder político garante, desde una racionalidad histórica o consuetudinaria, de un derecho que se entiende hecho, en parte, por fuera de la voluntad estatal. Así, en el mundo inglés, el derecho, si bien se reserva un claro componente coercitivo, no se expresa siempre así. Como lo indicó Hart, en la mentalidad inglesa el imperativo y la coercibilidad dura suelen representarse fundamentalmente como características del derecho penal (Hart, 1998, pp. 34-35 y 53).

Por tanto, fuera de este campo jurídico, la norma no hace tanto énfasis en la sanción, de allí que varias veces se presente como una permisión, pues en el fondo subyace, por lo menos más que en la tradición continental, el principio de colaboración del derecho y del Estado frente al ciudadano, como es de esperarse

\footnotetext{
${ }^{14}$ Desde la parte histórica, ver: (Fioravanti, 1998. pp. 25-35). Desde la parte dogmática: (Whittaker, 2008, pp. 37-83).
} 

mirada más allá del "Último mohicano"

en un sistema pragmático e historicista. Todo lo contrario a lo sucedido con el Estado europeo continental, el cual, por su fundamento y por su cultura, ha sido más proclive a un derecho sancionador. No se está diciendo, en modo alguno, que el Common Law carezca de coercibilidad y de sanciones-amenaza, sino que no hace tanto énfasis en dicho aspecto al momento de presentarse la norma jurídica.

Además, este matiz diferenciador se observa también en sus fundamentos filosóficos: "La teoría de Hart es una reflexión de Hume, mientras que la de Kelsen refleja a Kant -el Kant de la primera Crítica..., debe añadirse-" (Paulson, 2005, p.1158). Fundamentos que no chocan con los aspectos culturales a los que antes se aludió: Kelsen, al separar el ser del deber ser siguiendo la tradición continental, abrió el camino para una teoría de la norma prohibitiva; Hart, al momento de plantear su teoría sobre las prácticas sociales o las creencias del partícipe como consecuencia de la tradición británica, despejó la vía para una concepción de la norma más allá del esquema prohibitivo.

Añadamos, por demás, que Kelsen reconoció en algún momento que para la formulación de algunas ideas de su TPD, se basó exclusivamente en experiencias jurídicas particulares; verbigracia, la teoría de la unidad entre derecho y Estado le surgió del análisis del sistema austríaco; por tanto, dado que "esa teoría del Estado es una parte esencial de la Teoría pura del derecho, a esta puede considerársele como una teoría específicamente austríaca" (Kelsen, 2008, p.120).

En fin, Kelsen y Hart conciben pues una teoría general desde su presupuesto cultural, a la vez que filosófico. Esto lleva, como ya lo dije, a que Hart deba ampliar el marco de identificación de la norma kelseniana del positivismo (kantiano en lo filosófico e imperativista en lo cultural), para darle así cabida en el mundo anglosajón (humeano en lo filosófico e imperativista a la vez que promocional en lo cultural).

A todo esto le sumo un elemento altamente conflictivo en la Teoría Pura del Derecho, pero que podrá servir para comprender de mejor manera la postura kelseniana: la paz como fin del derecho ${ }^{15}$. Kelsen consideró que el derecho solo

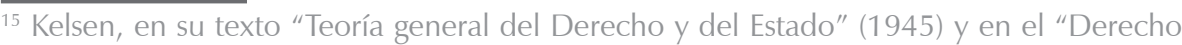
como orden constrictivo" (1949), señaló que el derecho, en tanto que controla las conductas coactivamente, promociona la paz. Por ejemplo, refiriéndose a la coercibilidad estatal, señaló: "Es de esta manera que el Derecho garantiza la paz dentro de la comunidad jurídica. He aquí la esencia del Derecho, que es una específica técnica social. Y si la paz es un valor, un fundamental valor social, helo aquí al valor del Derecho, que es paz". Kelsen en: (Kelsen, y Cossio, 1952 p. 60). En cambio, en la segunda edición de la TPD, habló de "seguridad colectiva", para restarle así el impacto axiológico que puede tener la finalidad "paz": "Cuando el orden jurídico determina las condiciones bajo las cuales la coacción, como fuerza física, debe ser ejercida, así como los individuos que deben hacerlo, protege a los individuos a él sometidos contra el uso de la fuerza por parte de otros individuos. Cuando esa protección alcanza cierta medida mínima se habla de seguridad
} 
podría lograr la paz (entendida como convivencia desde la mentalidad de un hombre asustado por la fragilidad de los sistemas democráticos y control de su época) mediante la prohibición de ciertas conductas y mediante la sanción a los transgresores.

Si se concibe el derecho como un orden coactivo, y se toman en consideración sólo aquellas normas que estatuyen sanciones, es decir, que estatuyen actos coactivos, como reacciones contra una conducta calificada como ilícita, tendremos que el derecho es una reacción contra lo ilícito; y, por tanto, como Tomás de Aquino, lo dice, en Summa theologica, 1-11, 96, artículo 5, sólo los malos, pero no los buenos, estarían sujetos al derecho (Kelsen, 2005, p. 126).

El derecho debía pues mostrar sus dientes como la única forma de impedir un estado caótico o el fin del modelo de convivencia aceptable desde su lógica democrática y desde su concepto privilegiado de Estado liberal de derecho ${ }^{16}$, que, como se sabe, justifica la intervención estatal en materia jurídica solo si ésta es para evitar o corregir una conducta considerada como desviada (por medio de hacerla imposible, difícil o desventajosa gracias a una sanción negativa), en tanto dicha conducta afectaría la paz social (Bobbio, 1990, pp. 371-385; López, 2000, p. 151).

Hart, por el contrario, consideraría que la convivencia, entendida ahora en clase de unas verdades morales obvias al interior del derecho, lo que refleja por demás el modelo judicial propio de la equity ${ }^{17}$ (en la que Hart litigó exitosamente antes de la Segunda Guerra Mundial ${ }^{18}$ ), no requiere, en todos los casos, normas prohibitivas,

colectiva, en cuanto es garantizada por el orden jurídico como orden social... La seguridad colectiva aspira a la paz, puesto que la paz es la ausencia del uso físico de la fuerza... La seguridad colectiva o la paz son funciones que -como ya se estableció- los órdenes coactivos designados como derecho poseen realmente en cierto momento de la evolución, si bien en grados diferentes. Esa función es un hecho objetivamente verificable" (Kelsen, 2005 , p. 50, 51 y 61 respectivamente). Pero como bien lo advirtió Bobbio, la "sustitución del concepto de paz por el de seguridad colectiva hace retroceder un paso el fin mínimo del derecho, pero no lo elimina: lo hace más vago, menos específico, pero no lo suprime" (Bobbio, 1976, p. 14). Así, para Bobbio, Kelsen no renunció a consideraciones funcionales cuando aludió a esta finalidad.

${ }^{16}$ Una precisión: Kelsen, por su ideal de pureza metodológica en lo que atañe al derecho, no fue muy amplio en sus opiniones políticas y económicas. Por ello la academia se ha preguntado: ¿cuál es el modelo ideal de Estado para Kelsen? Si bien no hay respuesta unánime, hay quienes sostienen, justo por su teoría de la sanción negativa, que Kelsen defendió el Estado liberal de derecho (v.gr. Peces-Barba, 1983, pp. 322-323); otros, por su parte, consideran que Kelsen fue un defensor, en lo político y en lo económico, de la socialdemocracia y, por tanto, del Estado social de derecho (v.gr. Ruiz, 1986, pp. 194-195). Pero esto último, opino, no choca de plano con su criterio de que el derecho sólo actúa para repeler actos considerados como dañinos, idea que proviene del liberalismo político.

${ }_{17}$ Modelo fundado en principios generales con clara alusión a componentes morales (Falcón, 2005, pp. 79-108).

${ }^{18}$ No olvidemos que Hart mismo reconoció la importancia de su práctica profesional como 

mirada más allá del "Último mohicano"

aspecto que está más o menos claro si se observa la cultura inglesa que hace parte, junto con modelos más cercanos al Estado de bienestar, a lo que se ha llamado como "ordenamientos jurídicos promocionales", en los cuales se busca incentivar una conducta deseada haciéndola fácil o ventajosa (Bobbio, 1990, pp. 371-385; Garrido, 2002/2003, pp. 200-202). Aquí, el derecho coercitivo es una ultima ratio, la última línea de defensa de la comunidad, pero la vanguardia propiciadora de la convivencia serían normas permisivas, autorizativas; es decir, normas con sanciónpositiva. En estos ordenamientos, el control de la conducta ha pasado más por otros escenarios que por el derecho castigador mismo, cosa que tenía bien claro Hart, lo que lo acercó más al funcionalismo que al estructuralismo puro:

Si el reconocimiento de la importancia del derecho promocional o promotor puede tener algún efecto, no es tanto respecto del enfoque estructural de él cuanto respecto del enfoque funcional... La función de un ordenamiento jurídico no es únicamente la de controlar el comportamiento de los individuos, lo cual puede obtenerse mediante la técnica de las sanciones negativas, sino también la de encauzar los comportamientos hacia ciertos objetivos previamente establecidos. Eso se podrá conseguir preferentemente por medio de la técnica de las sanciones positivas y de los incentivos. Se dice que la concepción tradicional del derecho como ordenamiento coactivo se funda en el presupuesto del "hombre malo", cuyas tendencias antisociales deben ser sojuzgadas. Se puede decir que la consideración: del derecho como ordenamiento directivo parte de la presunción del hombre inerte, pasivo, indiferente, que debe ser estimulado, provocado, urgido. Creo, pues, que hoy es más correcto definir el derecho, desde el punto de vista funcional, como forma de control y de dirección social (Bobbio, 1976, p. 30).

\section{Conclusiones}

El debate Kelsen-Hart, sobre la estructura de la norma jurídica, permite muchas lecturas útiles para la historia de la filosofía del derecho, para la filosofía del derecho y para el derecho comparado. Para empezar, es un debate que nos aclara sus diferencias filosóficas a la vez que culturales. La objeción central de Hart (1998, pp. 49-53) es que reducir las normas a imperativos prohibitivos y a sanciones-castigos produce una distorsión en lo que el partícipe común entiende por derecho, distorsión que permite la uniformidad de una teoría, pero que la aleja de la realidad. Para Hart es vital producir una teoría que sea aceptada por el ciudadano educado partícipe del sistema y, para ello, la teoría debe reflejar la riqueza y la variedad de las normas que vive como prácticas sociales. Kelsen está más centrado en la coherencia de su edificio teórico y en su mayor generalidad, que le permita ser aplicado a todos los sistemas, asunto que lo lleva a uniformizar tanto la teoría de la norma como su concepción de la finalidad del derecho (Hart, 1998, p. 46 y 52). En cambio, Hart, en su propia teoría general, niega que haya una sola estructura normativa y una sola función que pueda explicar el derecho,

determinante en sus teorías positivistas (Orrego, 1995, p. 1132). 
por lo que el derecho tiene diferentes tipos de reglas y distintas funciones según el contexto y según la práctica social a la que aludamos (Paulson, 2005). Pero esto deja en claro dos aspectos. El primero, haciendo uso de una expresión ya conocida en la iusfilosofía ${ }^{19}$, Kelsen es un erizo, mientras Hart es un zorro ${ }^{20}$. El segundo es que ambos, al momento de plantear su teoría general, no pueden eludir elementos particulares que determinan su visión, tales como sus influencias filosóficas, de un lado, y sus contextos culturales, del otro. Ambos aspectos determinaron dicho debate sobre la estructura de la norma. Veamos.

Kelsen se vio en apuros para responder las críticas de Hart que iban más allá de un debate lógico. Kelsen eludió referirse expresamente al componente cultural del debate que se le planteó, aunque creo que, en el fondo, su teoría respondió a sus fundamentos filosóficos a la vez que al contexto cultural continental; y eludió tal cosa pues, de hacerlo, habría tenido muchas dificultades teóricas, ya que él predicaba una teoría descriptiva de los sistemas jurídicos en general, por lo que, de entrada, la TPD debía rechazar cualquier tipo de consideraciones extrajurídicas, como sería lo cultural de un sistema jurídico concreto. Pero bien supo Kelsen que esas críticas debían ser asumidas para poder seguir afirmando que la TPD, por ser formal y general, es aplicable al Common Law. Por todo ello planteó una corrección, más formal que material para Hart, que mejoró de todas maneras la presentación de su teoría: las normas con sanción-positiva, a pesar de ser reconocidas como tal en varias culturas (desde un "punto de vista interno"), no son normas plenas vistas desde el plano científico (aquí Kelsen estaría haciendo un juicio desde el "punto de vista externo" hartiano). Pero hasta aquí podría pensarse que este debate solo tiene interés para la historia de la iusfilosofía.

Sin embargo, estas críticas hartianas, repito, no buscaban el fin del estructuralismo kelseniano en el derecho, sino el reconocimiento de que la norma no es solo un conjunto de imputaciones prohibitivas y que la teoría general del derecho no puede reducirse a hacer juicios por fuera de las prácticas sociales. Estas correcciones las consideró necesarias Hart para posicionar de mejor manera la postura kelseniana, a la que consideraba en muchos aspectos como correcta, y para suavizar (en referencia a su "positivismo suave") afirmaciones que volvían débil su propio frente de batalla. Incluso, podemos acudir a las propias palabras de Hart al momento de relatar su encuentro con Kelsen en Berkeley, en 1961:

\footnotetext{
${ }^{19}$ Por ejemplo, la expresión de Kelsen como erizo, ha propiciado una buena compilación de textos de renombrados académicos: (Bernal, C. y Porciuncula, M., 2017).

${ }^{20}$ Isaih Berlin (1998) planteó una distinción entre el erizo y el zorro, basado en un poema de Arquíloco (que dice: "La zorra sabe muchas cosas, pero el erizo sabe una importante" (Berlin, 1998, p. 39). Los erizos logran reducir la complejidad del mundo a un puñado de ideas, pero pierden capacidad de explicar los casos difíciles que se encuentran en la realidad; en cambio, los zorros son más abiertos a la complejidad, aunque no logran la precisión y la coherencia teórica propia de los erizos.
} 

mirada más allá del "Último mohicano"

\begin{abstract}
Advertimos a nuestra gran audiencia de que podrían quedar decepcionados o aburridos, o ambas cosas: porque las preguntas que propusimos discutir podrían parecer excusablemente secas y técnicas, y nuestras diferencias serían meras disputas sobre detalles en el campo «positivista» de la jurisprudencia, lo que no tiene mayor interés para los que están fuera de ella. Yo expliqué que mi punto de vista era que el gran trabajo de Kelsen merecía el cumplido de un escrutinio detallado, y que con demasiada frecuencia se había usado como excusa para debate de cuestiones vastas y vagamente definidas, como el perennemente conocido 'Derecho Natural versus Positivismo Jurídico' (Hart, 1983, p. 286, traducción propia).
\end{abstract}

Es decir, Hart realizó un "escrutinio detallado" de la obra kelseniana por su relevancia, a la vez que como manera de fortalecer el positivismo, para evitar que dicha obra fuese usada impropiamente (por ciertos aspectos muy específicos como el que aquí mostré en torno a la sanción) en los debates cruciales de su época.

Todo esto queda más claro si se recuerda que Hart no dudó en respaldar a Kelsen ante los enemigos comunes, especialmente los que existían al interior del Common Law. Este trabajo mancomunado, ficcionalmente hablando, se puede ver en decenas de campos (uno de ellos fue la crítica a los "derechos subjetivos" 21 ), pero quisiera llamar la atención en tres aspectos. El primero fue la purificación de una fuente inspiradora común: John Austin [1790-1857]; autor que Hart consideraba esencial para poder cimentar de mejor manera el positivismo para la segunda mitad del siglo XX. El segundo fue la reacción mancomunada contra el realismo judicial, que consideraron ambos como el principal oponente en Estados Unidos. El tercero fue el frente común ante los embates moralistas como los de Fuller (1958,

\footnotetext{
${ }^{21}$ En aquel entonces se dieron muchos debates sobre si existían los "derechos subjetivos". En este debate participaron, obviamente, Kelsen y Hart con posturas complementarias. Kelsen, siendo normativista, no consideró al derecho subjetivo como una categoría independiente: "Si se pone de lado la suposición de derechos naturales, y sólo se reconoce los derechos estatuidos por un orden jurídico positivo, resulta entonces que el derecho subjetivo en el sentido discutido, presupone una obligación jurídica correspondiente; más, consiste en esa obligación jurídica" (Kelsen, 2005, p. 143). Esto es, que no hay distinción entre derecho subjetivo y derecho objetivo. Igualmente, consideró que la concepción del derecho subjetivo se vio favorecida por aspectos ideológicos del capitalismo (de allí el rechazo que esta categoría generó en los autores soviéticos) en su reivindicación de la propiedad privada: "No es función esencial del derecho objetivo estatuir tales derechos subjetivos en sentido técnico, a diferencia de la función consistente en estatuir obligaciones jurídicas. Constituye una configuración posible, pero no necesaria, del contenido del derecho objetivo; una técnica particular de que puede servirse el derecho, pero que de ningún modo está obligado a hacerlo. Se trata de la técnica específica del orden jurídico capitalista, en cuanto éste garantiza la institución de la propiedad privada, atendiendo, por lo tanto, en forma muy especial al interés individual". (Kelsen, 2005, p. 148). En el fondo, la acusación a los positivistas de defender el "derecho subjetivo" como una entidad propia dentro del derecho solo se predicaría de pocos sectores del positivismo, puesto que Bentham, Kelsen y Hart, por dar solo tres nombres, rechazaron que el "derecho subjetivo" tuviese un contenido semántico propio, aunque sí tendría un interés ideológico y pragmático (Rubio, 1987, pp. 295-302).
} 
pp. 630-672), para lo cual Hart debió matizar la fuerte separación entre moral y derecho presente en la TPD (favoreciendo así la defensa del positivismo en el contexto anglosajón ${ }^{22}$ ). En este esquema más general es que puede entenderse la potencialidad y la trascendencia de Hart como consolidador del positivismo de su época. Y fue tal su labor que logró, en cierto sentido, con sus críticas a Kelsen y con sus luchas mancomunadas, darle mayor aliento al positivismo, brindarle un nuevo aire a las discusiones que él estaba librando, aire que tal vez ya no tenía la TPD y que permitió, junto con otras cosas, que hubiese positivismo para mucho rato más. Todo esto es de suma importancia para un lector contemporáneo.

Pero también es importante para el lector contemporáneo que, gracias a dicho debate sobre la sanción en la norma jurídica, entra a terrenos propios de la antropología jurídica, de un lado, y más especialmente al derecho comparado, del otro, puesto que, en el fondo, se vislumbra el contenido cultural de la norma jurídica asociada a la finalidad axiológica de la misma, aspectos ante los cuales la tradicional filosofía del derecho se ha quedado corta y que son asuntos que aún siguen teniendo vigencia (Culver, 2001). Asumir este debate se constituye, pues, en una buena manera de comprender las vicisitudes culturales de la forma de concebir el derecho en dos modelos tan distintos, pero que, por la globalización, se ponen hoy día en fuerte comunicación.

En conclusión, Hart no fue el último mohicano cuya estela desapareció gracias a Dworkin, sino que sigue siendo un autor que tiene mucho que decirle a quien desee estar mejor habilitado para comprender la iusfilosofía y los sistemas jurídicos contemporáneos, sea estudiante o expertọ

\section{Referencias}

Berlin, I. (1998). El erizo y la zorra. C, Aguilar (Trad.). Barcelona: Muchnik Editores.

Bernal, C. y Porciuncula, M. (Eds.). (2017). Kelsen para erizos: ensayos en honor a Stanley L. Paulson. Bogotá: Universidad Externado de Colombia.

Bobbio, N. (1976). Hacia una teoría funcional del derecho. En Bacqué, J. A. et al (Ed.), Derecho, Filosofía y Lenguaje: homenaje a Ambrosio L. Gioja (14-30). Buenos Aires: Astrea.

Bobbio, N. (1990). Contribución a la Teoría del Derecho. A, Ruiz Miguel (Trad.). Madrid: Debate.

\footnotetext{
${ }^{22}$ Entonces, aludir a contenidos mínimos de moral en el derecho, como ya se explicó, en contravía de Kelsen, sirvió para posicionar de mejor manera al positivismo dentro de los debates que Hart estaba dando en su momento (Orrego, 1995, p. 1097).
} 
Bulygin, E. y Mendonca, D. (2005). Normas y sistemas normativos. Madrid: Marcial Pons.

Bulygin, E. (1976). Sobre la regla de reconocimiento. En Bacqué, J. A. et al (Ed.), Derecho, Filosofía y Lenguaje: homenaje a Ambrosio L. Gioja (31-39). Buenos Aires: Astrea.

Bulygin, E. (1991). Regla de reconocimiento: ¿norma de obligación o criterio conceptual? Réplica a Juan Ruiz Manero. Doxa, (9), 311-318.

Bulygin, E. (2009). La importancia de la distinción entre normas y proposiciones normativas. En Bulygin, E.; Atienza, M. \& Bayón, J.C. (Ed.), Problemas lógicos en la teoría y práctica del Derecho (11-14). Madrid: Fundación Coloquio Jurídico Europeo.

Carranza Torres, L. (2014, 21 de noviembre). Cazador de espías, filósofo del derecho. Comercio y Justicia.

Clark, R. S. (1969). Hans Kelsen's Pure Theory of Law. Journal of legal education, 22, 170-196.

Cracogna, D. (1986). La fundamentación normativa del derecho en Hart y Kelsen. En Laclau, M. \& Cracogna, D. (Comps.), Teoría general del derecho: sus problemas actuales, estudios en homenaje a Julio C. Cuesto Rúa (47-64). Buenos Aires: Editorial Heliasta.

Culver, K. (2001). Leaving the Hart-Dworkin Debate, University of Toronto Law Journal, (51), 367-398.

Dworkin, R. (1989). Los derechos en serio (2ª ed). Guastavino, M. (Trad.). Barcelona: Ariel.

Falcón y Tella, M. J. (2005). La equity angloamericana. Foro, Nueva época, (1), 79-108.

Fioravanti, M. (1998). Los derechos fundamentales: apuntes de historia de las constituciones. Martínez Neira, M. (Trad). (2 ${ }^{\underline{a}}$ ed). Madrid: Trotta.

Fuller, L. (1958). Positivism and Fidelity to Law: A Reply to Professor Hart. Harvard Law Review, 71(4), 630-672.

García Ramírez, J. (2011). Concepciones sobre la norma jurídica. Una aproximación textual (2ª . ed). En Valderrama, F. (Coord.), Teoría del derecho, (171-212). 
Garrido, M. (2002/2003). Derechos y garantías jurídicas en el discurso de la protección de la familia. Revista Telemática de Filosofía del Derecho, (6), 193-203.

Gómez, A. (1976). Acerca de la vinculación de la regla de reconocimiento con las restantes reglas secundarias. En Bacqué, J. A. et al (Ed.), Derecho, Filosofía y Lenguaje: homenaje a Ambrosio L. Gioja (47-53). Buenos Aires: Astrea.

Hart, H. L. A. (1968). Kelsen's doctrine of the Unity of Law. En Munitz, M. \& Kiefer, H. (Ed.), Ethics and Social Justice (208-270). Albany NY: State University of New York Press.

Hart, H.L.A. (1983). Kelsen visited. En Hart, H.L.A., Essays in Jurisprudence and Philosophy (286-308). Oxford: Clarendon Press.

Hart, H. L. A. (1994). La teoría de Kelsen sobre la unidad del derecho. En Casanovas Romeu, P. \& Moreso, J. J. (Ed.), El ámbito de lo jurídico: lecturas de pensamiento jurídico contemporáneo (383-421). Barcelona: Crítica.

Hart, H.L.A. (1998). El concepto de derecho, trad. Genaro Carrió. Buenos Aires: Abeledo Perrot.

Hart, J. (1998). Ask me no more. London: Halban Publishers.

Kelsen, H. y Cossio, C. (1952). Problemas escogidos de la teoría pura del derecho: teoría egológica y teoría pura. Buenos Aires: Editorial Guillermo Kraft Ltda.

Kelsen, H. (1941). The Law as a Specific Social Technique. The University of Chicago Law Review, 9 (1), 75-97.

Kelsen, H. (1962), Derogation. En: Newman, R. (Ed.), Essays in Jurisprudence in Honor of Roscoe Pound (339-355). Indianapolis-New York: The Bobbs-Merrill Co.

Kelsen, H. (2005). Teoría pura del derecho (14a․ Ed). R, Vernengo (Trad.). México: Porrúa.

Kelsen, H. (2008). Autobiografía. L, Villar (Trad.). Bogotá: Universidad Externado.

Lacey, N. (2004). A life of H. L. A. Hart. The nightmare and the noble dream. Oxford: Oxford University Press.

Lloredo, L. (2017). Muertes y resurrecciones del positivismo jurídico: una crisis de doscientos años de duración. Doxa, (40), 249-278. 
López Medina, D. (2000). ¿Existe una "ciencia jurídica"? Los modelos de la "cientificidad" del Derecho en Colombia. En Castro, S. (Ed.), La reestructuración de las ciencias sociales en América Latina (137-156). Bogotá: Pensar, Instituto de Estudios Sociales y Culturales.

Márquez, J. (1985). Hart y Kelsen: regla de reconocimiento y norma básica. Persona y Derecho, (12), 163-188.

Orrego, C. (1995). Antecedentes iusfilosóficos de El concepto de derecho de H.L.A. Hart. Boletín Mexicano de Derecho Comparado, Nueva Serie, XXVIII(84), 1091-1137.

Paulson, Stanley (2005). Normativismo continental y su contraparte británico. ¿Qué tan diferentes son? Boletín Mexicano de Derecho Comparado, Nueva Serie, XXXVIII(114), 1139-1163.

Peces-Barba, G. (1983). El problema de la justicia en Kelsen: notas de lectura. Revista Española de Derecho Constitucional, 3(8), 317-325.

Raz, J. (1980). The concept of a legal system. An introduction to the theory of legal system. 2a. ed. Oxford: Oxford University Press.

Raz, J. (1993). En memoria de H.L.A. Hart. Doxa, (13), 27-30.

Robles, G. (1980). Consideraciones sobre la teoría de la norma jurídica en Kelsen. Revista de la Facultad de Derecho de la Universidad Complutense, (60), 47-64.

Rosamund, T. (1991). Espionage and secrecy: The official secrets acts 1911-1989 of the United Kingdom. London: Routledge.

Rubio, A. (1987). Teoría del derecho y derecho subjetivo en Alf Ross. Anuario de filosofía del derecho, (4), 279-302.

Ruiz, J. (1986). Sobre la crítica de Kelsen al marxismo. Doxa, (3), 191-231.

Ruiz, J. (1990). Jurisdicción y Normas. Madrid: Centro de Estudios Constitucionales.

Ruiz, J. (1991). Normas independientes, criterios conceptuales y trucos verbales. Respuesta a Eugenio Bulygin. Doxa, (9), 281-293.

Torres Muro, I. (2005). H.L.A. Hart al desnudo. Revista Española de Derecho Constitucional, (75), 359-368. 
White, G. E. (2005). Book review: Getting close to H.L.A. Hart: A Life of H.L.A. Hart: The Nightmare and the Noble Dream by Nicola Lacey (Oxford: Oxford University Press, 2004) pages i-xxii, 1-422. Melbourne University Law Review, (29), 317-336.

Whittaker, S. (2008). El precedente en el derecho inglés: una visión desde la ciudadela. Revista Chilena de Derecho, 35(1), 37-83. 